\title{
It Is Time
}

\section{Kiran K. Turaga, MD, MPH ${ }^{1}$, T. Clark Gamblin, MD, MS, MBA ${ }^{2}$, Robert Edwards, MD, $\mathbf{P h D}^{3}$, H. Richard Alexander, $\mathrm{MD}, \mathrm{PhD}^{4}$, and David Bartlett, $\mathrm{MD}^{5}$}

${ }^{1}$ Department of Surgery, University of Chicago, Chicago, IL; ${ }^{2}$ Department of Surgery, Medical College of Wisconsin, Milwaukee, WI; ${ }^{3}$ Department of Obstetrics and Gynecology, University of Pittsburgh, Pittsburgh, PA; ${ }^{4}$ Department of Surgery, Rutgers Cancer Institute of New Jersey, New Brunswick, NJ; ${ }^{5}$ Department of Surgery, University of Pittsburgh, Pittsburgh, PA

In this series, we present selected articles presented at the SSO International Symposium of Regional Therapies at Jacksonville in 2018. The symposium, which was supported by the Society of Surgical Oncology, resulted in a record turnout and a great scientific discussion. In addition to laying grounds for scientific advances and collaboration, the meeting provided a family-friendly venue for networking, mentoring, and new ideas.

Management of regional metastases with locoregional therapies has long been studied, and the year 2018 saw some remarkable advances. Evidence regarding the role of locoregional (HIPEC) therapy for peritoneal metastases of colorectal and ovarian origin was presented, which confirmed the efficacy of intraperitoneal therapy in ovarian tumors and in a select group of patients with peritoneal metastases from colorectal malignancies. The science behind melanoma immunotherapy has been supercharged, and the results of new trials of checkpoint inhibitors, elucidation of mechanisms of "cold" immune environments, IDO inhibitors, and inhibition of the MAP-Kinase pathway and the role of such therapies in adjuvant settings became mainstream. The field of liver metastases has matured in its understanding of catheter-based, regional therapies, and the evolution of modern therapies, such as ALPPS, two-stage liver resections, and liver transplants. Regional perfusion clinical trials remain active, and results are awaited.

The articles presented in this series focus on three themes: (1) the novel application of regional therapies to benign and malignant disease; (2) the role of perioperative outcomes and toxicity on oncological outcomes; and (3) patient-centered (and specific) optimization of therapies. A visual abstract summary of the articles is depicted in Fig. 1a-1.

With the rapid advancements in the field, it is time that regional therapies for locally advanced disease continue to advance and augment evolving therapies. Momentum in collaboration through the development of cooperative working groups, consensus conferences, and novel societies are reflective of the heightened interest in this field. Simultaneous with advances in the management of these diseases, advances in imaging, pathology, and translational research need to occur. Come join us in Phoenix this year to contribute to this evolving field!

(C) Society of Surgical Oncology 2019

First Received: 15 January 2019;

Published Online: 29 April 2019

K. K. Turaga, MD, MPH

e-mail: kturaga@uchicago.edu 
A

\section{T-Vec for the Treatment of Advanced Melanoma}

\section{$N=27$, Retrospective Single Institution \\ Study}

Stage III or Stage IV Patients

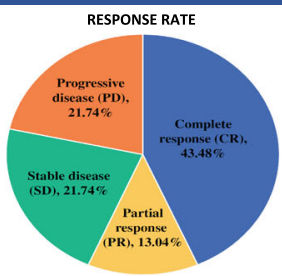

Perez et. al Ann Surg Onc 2019

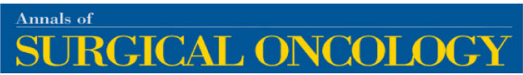

C

\section{Outcomes of LAMN with Remote Peritoneal Deposits}

10/11 patients with progression had cellular mucin deposits

CMPD (cellular mucinous peritoneal disease) AMPD (acellular mucinous peritoneal disease)

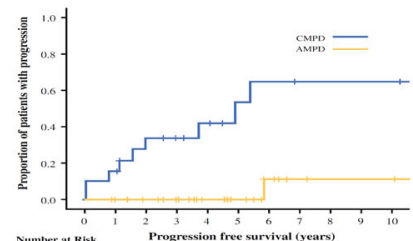

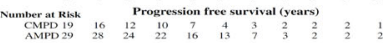

Roxburgh et. al Ann Surg Onc 2019

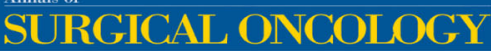

$\mathbf{E}$

\section{Toxicity and Survival by Temperature and Time of Perfusion in ILP for Melanoma}

Multivariate Odds Ratio for Toxicity and Survival by Time and Temperature

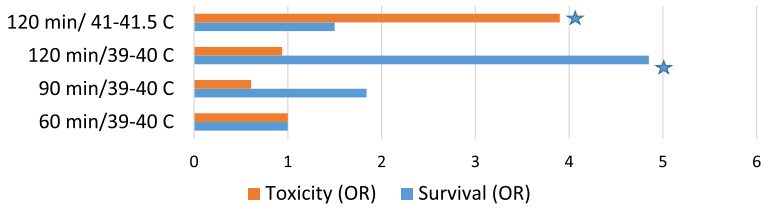

Katsarelias et. al Ann Surg Onc 2019

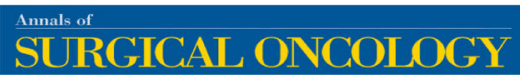

G

\section{Restrictive Fluid Therapy for CRS+HIPEC}

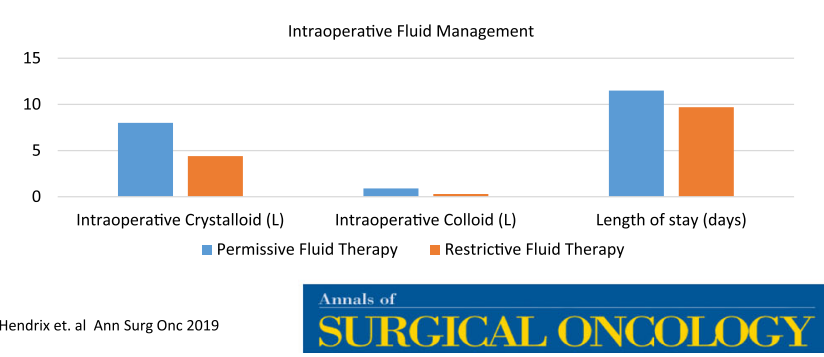

B

\section{Elective Regional Therapy Treatment for Hepatic} Adenoma

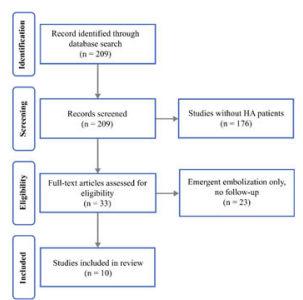

Silva et. al Ann Surg Onc 2019
66 patients with 138 adenomas

25 patients underwent

embolization

35 underwent ablation

Repeat Procedures in 13\% only
Systematic Review

D

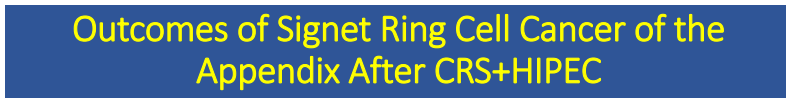

OS for patients with High Grade Mucinous carcinoma peritonei (HGMCP) with signet ring cells after CRS+HIPEC at 5 years was 25\% with worse prognosis for node positivity

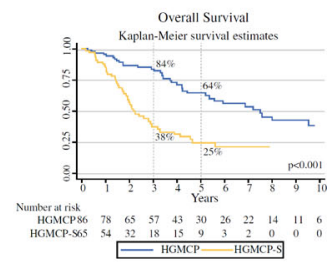

Munoz-Zuluaga et. al Ann Surg Onc 201

\section{SURGICAL ONCOLOGY}

\section{$\mathbf{F}$}

\section{Toxicity and Survival of Repeated ILP for Melanoma}

$65 \%$ complete response $(C R)$ rate with repeated ILP in those that had original $C R$

Toxicity similar between $1^{\text {st }}, 2^{\text {nd }}, 3^{\text {rd }}$ and $4^{\text {th }}$ ILP (Wieberdink Grade III or higher 37.5 vs. 33 vs. 42 vs. $25 \%$ )

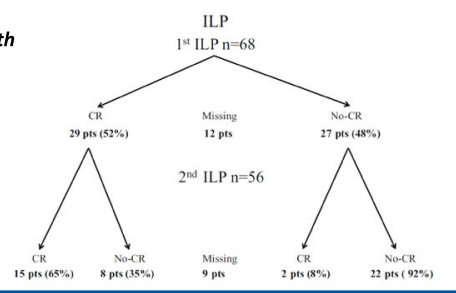

Belgrano et. al Ann Surg Onc 2019

SURGICAL ONCOLOGY

\section{H}

\section{Anesthesia and Pain Management for Young Adults Undergoing CRS+HIPEC}

CRS and HIPEC in Young adults is associated with

-significant renal injury despite renal protective strategies

-morbidity

-need for narcotics despite epidural

$\%$ Increase in Serum Creatinine

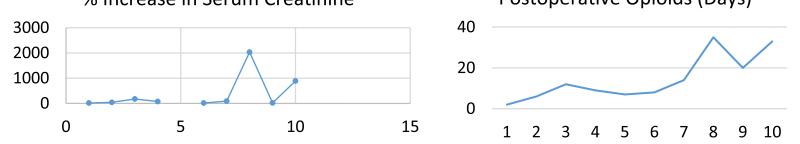

Anghelscu et. al Ann Surg Onc 2019

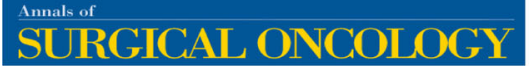

FIG. 1 a-m Visual abstracts of cancer regional therapies series 
I

Pleuropulmonary Recurrence after CRS+HIPEC for PMP Syndrome from Appendiceal Neoplasms

61 patients (16\%) developed pleuropulmonary recurrence who had lower survival Odds of Recurrence (Odds Ratio)

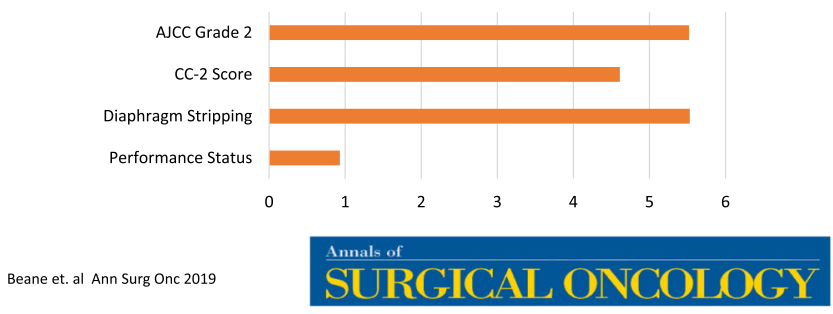

$\mathbf{K}$

\section{Sites of Recurrence after CRS+HIPEC}

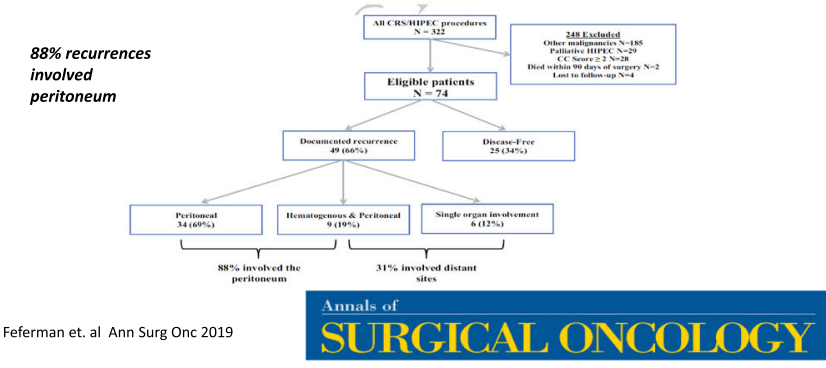

$\mathbf{M}$

\section{Appendiceal Cancer Patient Specific Organoids}

9 of 12 biospecimens (75\%) were able to be used for organoid development

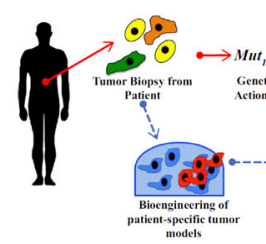

Votanopoulos et. al Ann Surg Onc 2019
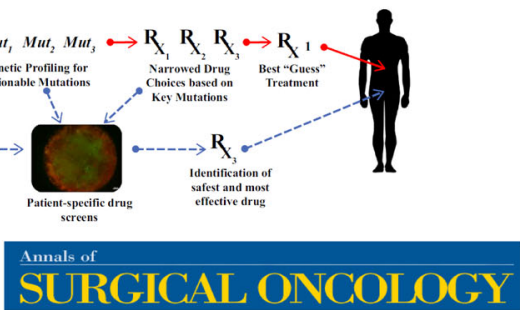

FIG. 1 continued

\section{REFERENCES}

1. Perez MC, Miura JT, Naqvi SMH, et al. Talimogene Laherparepvec (TVEC) for the treatment of advanced melanoma: a single-institution experience. Ann Surg Oncol. 2018;25:3960. h ttps://doi.org/10.1245/s10434-018-6803-0.

2. Silva JP, Klooster B, Tsai S, et al. Elective regional therapy treatment for hepatic adenoma. Ann Surg Oncol. 2018. https://doi. org/10.1245/s10434-018-6802-1.

3. Roxburgh CS, Fenig YM, Cercek A, et al. Outcomes of lowgrade appendiceal mucinous neoplasms with remote acellular mucinous peritoneal deposits. Ann Surg Oncol. 2018. https://doi. org/10.1245/s10434-018-7003-7.

4. Munoz-Zuluaga C, Sardi A, King MC, et al. Outcomes in peritoneal dissemination from signet ring cell carcinoma of the
$\mathbf{J}$

Post Operative Complications Predict Cancer Related Survival after CRS + HIPEC

Grade $3-4$ complications in $24 \%$ of population

Higher complication rate, lower survival HR 1.3(1.06-1.65)

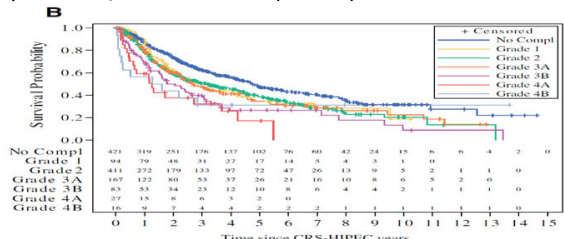

Choudry et. al Ann Surg Onc 2019

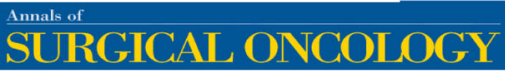

$\mathbf{L}$
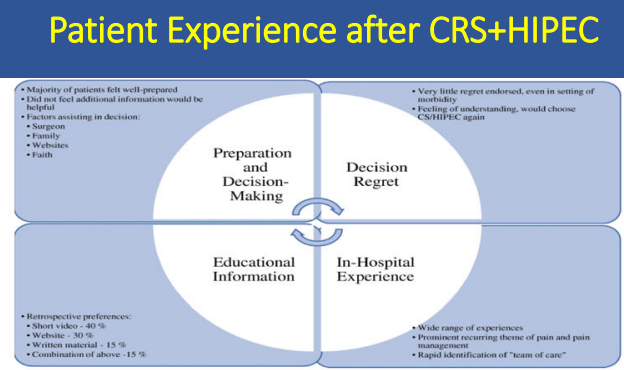

Fransescutti et. al Ann Surg Onc 2019

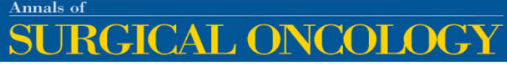

appendix treated with cytoreductive surgery and hyperthermic intraperitoneal chemotherapy. Ann Surg Oncol. 2018. https://doi. org/10.1245/s10434-018-7007-3.

5. Katsarelias D, Rådbo E, Ben-Shabat I, et al. The effect of temperature and perfusion time on response, toxicity, and survival in patients with in-transit melanoma metastases treated with isolated limb perfusion. Ann Surg Oncol. 2018;25:1836. https://doi.org/ 10.1245/s10434-018-6459-9.

6. Belgrano V, Pettersson J, Nilsson JA, et al. Response and toxicity of repeated isolated limb perfusion (re-ILP) for patients with intransit metastases of malignant melanoma. Ann Surg Oncol. 2019. https://doi.org/10.1245/s10434-018-07143-4.

7. Hendrix RJ, Damle A, Williams C, et al. Restrictive intraoperative fluid therapy is associated with decreased morbidity and length of stay following hyperthermic intraperitoneal 
chemoperfusion. Ann Surg Oncol. 2018. https://doi.org/10.1245/ s10434-018-07092-y.

8. Anghelescu DL, Brown CL, Murphy AJ, et al. Anesthesia and pain management for cytoreductive surgery and hyperthermic intraperitoneal chemotherapy for desmoplastic small round cell tumors in children, adolescents, and young adults. Ann Surg Oncol. 2018. https://doi.org/10.1245/s10434-018-6808-8.

9. Choudry MHA, Shuai Y, Jones HL, et al. Postoperative complications independently predict cancer-related survival in peritoneal malignancies. Ann Surg Oncol. 2018;25:3950. https://d oi.org/10.1245/s10434-018-6823-9.

10. Beane JD, Wilson GC, Sutton JM, et al. Pleuropulmonary recurrence following cytoreductive surgery and hyperthermic intraperitoneal chemoperfusion for appendiceal Pseudomyxoma peritonei. Ann Surg Oncol. 2019. https://doi.org/10.1245/s10434018-07091-z.

11. Feferman Y, Solomon D, Bhagwandin S, et al. Sites of recurrence after complete cytoreduction and hyperthermic intraperitoneal chemotherapy for patients with peritoneal carcinomatosis from colorectal and appendiceal adenocarcinoma: a tertiary center experience. Ann Surg Oncol. 2018. https://doi.org/10.1245/s104 34-018-6860-4.

12. Francescutti VA, Maciver AH, Stewart E, et al. Characterizing the patient experience of CS/HIPEC through in-depth interviews with patients: identification of key concepts in the development of a patient-centered program. Ann Surg Oncol. 2019. https://doi. org/10.1245/s10434-018-07120-x.

13. Votanopoulos KI, Mazzocchi A, Sivakumar H, et al. Appendiceal cancer patient-specific tumor organoid model for predicting chemotherapy efficacy prior to initiation of treatment: a feasibility study. Ann Surg Oncol. 2018. https://doi.org/10.1245/ s10434-018-7008-2.

Publisher's Note Springer Nature remains neutral with regard to jurisdictional claims in published maps and institutional affiliations. 